\title{
CARACTERIZAÇÃO MORFOAGRONÔMICA DE STYLOSANTHES PERTENCENTE À COLEÇÃO DA UEFS.
}

\section{Larissa de Souza Pereira ${ }^{1}$; Claudinéia Regina Pelacani²; Aritana Alves da Silva ${ }^{3}$.}

1. Bolsista PIBIC/CNPq, Graduanda em Agronomia, Universidade Estadual de Feira de Santana, e-mail: lary_xique@hotmail.com

2. Orientadora, Departamento de Ciências Biológicas, Universidade Estadual de Feira de Santana, e-mail: claudineiapelacani@gmail.com

3. Mestranda em Recursos Genéticos Vegetais, Departamento de Ciências Biológicas, Universidade Estadual de Feira de Santana, e-mail: aritana.agronomia@gmail.com

PALAVRAS-CHAVE: Estilosantes, sementes, caracterização.

\section{INTRODUÇÃO}

O gênero Stylosanthes possui 50 espécies distribuídas em todo o mundo (FLORA DO BRASIL, 2020), sendo o Brasil um dos países mais importante para o gênero, com 31 das espécies descritas. Destacam-se pelo seu potencial forrageiro, pois apresenta alta produção de biomassa com elevado nível de proteína e excelente qualidade de forragem, além de ser tolerante ao déficit hídrico (COSTA, 2006). As espécies desse gênero são propagadas preferencialmente por sementes e o seu plantio é realizado comumente em consórcio com gramíneas porém se faz necessário identificar, caracterizar e propagar materiais mais promissores para atender a demanda de produtores especialmente de regiões áridas e semiáridas do nordeste (OLIVEIRA;QUEIRÓZ, 2016). Objetivou-se intensificar as ações de caracterização morfoagronômica de germoplasma "semente" conservado, visando avaliar a variabilidade genética ainda nos estágios iniciais do desenvolvimento das plantas, bem como a multiplicação dos acessos armazenados para fins de renovação do BGF-Horto Florestal da UEFS.

\section{MATERIAL E MÉTODOS}

Os experimentos foram realizados na Unidade Experimental Horto Florestal da Universidade Estadual de Feira de Santana. A caracterização de sementes armazenadas (BGFUEFS) e teste de viabilidade foram realizadas no Laboratório de Germinação (LAGER) e a caracterização morfológica das mudas foram realizados em viveiro. As atividades envolvendo renovação do BGF como coleta de sementes, beneficiamento, secagem, separação, identificação e armazenamento dos lotes ocorreram em ambos espaços do Horto Florestal.

\section{Caracterização do material vegetal}

As sementes utilizadas no experimento foram obtidas a partir de acessos (Tabela 1) oriundos da coleção de germoplasma de forrageiras da UEFS (BGF-UEFS).

Tabela 1. Descrição dos acessos utilizados. Feira de Santana, BA 2019-2020.

\begin{tabular}{lcl}
\hline \multicolumn{1}{c}{ Acesso } & Origem & Coordenadas \\
\hline $\mathbf{1}$ (BGF 14- P115-2) & Muquém do São Francisco, BA & $12^{\circ} 13^{\prime} 062^{\prime \prime} \mathrm{S} 43^{\circ} 52^{\prime} 018^{\prime \prime} \mathrm{O}$ \\
$\mathbf{2}$ (BGF 14-039) & Canarana, BA & $11^{\circ} 48^{\prime} 597^{\prime \prime} \mathrm{S} 41^{\circ} 11^{\prime} 452^{\prime \prime} \mathrm{O}$ \\
$\mathbf{3}$ (BGF 14-230) & Ibotirama, BA & $12^{\circ} 37^{\prime} 311^{\prime \prime} \mathrm{S} 42^{\circ} 11^{\prime} 452^{\prime \prime O}$ \\
\hline
\end{tabular}

\section{Caracterização de sementes armazenadas}

A partir do 'pool' de sementes de cada acesso escolhido, uma subamostra de 200 sementes foi dividida em quatro repetições $(n=50)$ e analisadas quanto às medidas de comprimento (distância do ápice à base), largura e espessura (região mediana). Utilizando essa mesma subamostra, foram obtidos pesos das massas frescas e secas (g) para obtenção do CU\% (RAS, 2009). Uma segunda subamostra de sementes de cada acesso foram utilizadas e obtidas as massas (g) de 100 e 1000 sementes com auxílio de balança analítica $(0,0001 \mathrm{~g})$. Utilizando uma mini-cartela de cores RHS (Royal Horticultural Society), foi 
comparada a coloração da testa das sementes para os três acessos de estilosantes.

\section{Viabilidade das sementes}

Um total de 100 sementes de cada acesso foi utilizado para o teste de viabilidade. Previamente as sementes passaram por pré-tratamento de superação de dormência tegumentar (externa), utilizando lixa $\mathrm{n}^{\circ} 80$ e desinfestadas em seguida. As condições gerais do ensaio foram: uso de placa de Petri $(90 \times 15 \mathrm{~mm})$ contendo duas folhas de papel de germinação estéril previamente umidificado com água destilada; câmaras de germinação tipo B.O.D. ajustada nas temperaturas de $20 / 30{ }^{\circ} \mathrm{C}$ (noite/dia) e fotoperíodo de 12 horas. A unidade experimental foi composta de quatro repetições de 25 sementes para cada acesso estudado. A partir das observações diárias, por um período de 14 dias consecutivos, foi possível determinar: taxa de germinação total (\%) (através do aparecimento da raiz primária), tempo médio de geminação (dias) e índice de velocidade de germinação $\left(\operatorname{sem} \cdot \operatorname{dia}^{-1}\right)$.

\section{Multiplicação e caracterização morfológica das mudas}

Após análises e obtenção dos dados de germinação, 14 dias após a semeadura as plântulas foram transplantadas para recipientes descartáveis $(300 \mathrm{~mL})$ com substrato comercial Biomix, e mantidas em bancadas de concreto em ambiente tipo telado. Tratos culturais como irrigação, retirada de plantas invasoras foram realizados periodicamente. Após três meses do transplantio, foi realizada a caracterização do material vegetal.

Foram avaliadas 12 plantas de cada acesso. Para essa caracterização os descritores utilizados foram baseados em Costa (2006) e Karia (2008), são eles: DP - Diâmetro da Planta $(\mathrm{mm}) ; \mathbf{E P}$ - Estatura de planta (cm); DP/EP; CFC - Comprimento do Folíolo Central (mm); LFC - Largura do Folíolo Central das Plantas (mm); NF - Número de folhas observadas a partir do nível do solo até a última folha. Obedecendo os pressupostos estatísticos, os recipientes foram mantidos em blocos casualizados e cada parcela experimental foi constituída de quatro mudas por acesso totalizando 36 mudas avaliadas. Testes de normalidade foram empregados para que as análises estatísticas e as diferenças entre as médias fossem realizadas. O programa estatístico utilizado foi o Sisvar, os dados foram submetidos à análise de variância e as médias comparadas entre si pelo teste de Tukey a 5\% de probabilidade.

\section{RESULTADOS E/OU DISCUSSÃO}

\section{Caracterização das sementes}

Foram observadas variação na coloração do tegumento externo das sementes e das características biométricas (Tabela 2). Prevaleceu as cores cores Brown (RHS 199') para aquelas dos acessos 1 e 3 e Orange Brown (RHS N170A) para as do acesso 2.

As sementes apresentaram médias de comprimento variando entre 1,91 a 2,04 mm; a largura variou de 1,36 a 1,45 mm, tendo os acessos 1 e 2 como os melhores acessos para as duas variáveis analisadas ( $\mathrm{p}<0,05)$. As porcentagens de CU variaram entre 4,3 a 5,3\% (dados não apresentados). Em relação ao peso de 100 e 1000 sementes, foram observadas variações entre os acessos estudados, destacando aquelas do acesso 2 com maiores massas e dimensões de comprimento e largura. Uma outra observação realizada nas sementes foi a presença do tegumento rígido, impondo uma dormência tegumentar ou mesmo morfofisiológica. Esta característica é comum em sementes de Stylosanthes (ARAÚJO et al., 2000; DEMINICIS et al., 2006). Nesse caso, para qualquer teste de germinação, acompanhamento da embebição e da multiplicação de sementes do BGFsemente devem ser precedidas pela escarificação do tegumento externo. 
Tabela 2. Valores médios biométricos de sementes de Stylosanthes

\begin{tabular}{llccc}
\hline Acesso & $\begin{array}{l}\text { CS } \\
(\mathbf{m m})\end{array}$ & $\begin{array}{c}\text { LS } \\
(\mathbf{m m})\end{array}$ & $\begin{array}{c}\text { P100S } \\
\text { (g) }\end{array}$ & $\begin{array}{c}\text { P1000S } \\
(\mathbf{g})\end{array}$ \\
\hline $\mathbf{1}$ (BGF 14-P115-2) & $2,04 \mathrm{a}^{* *}$ & $1,45 \mathrm{a}^{* *}$ & $0,1637 \mathrm{c}^{* *}$ & $1,6517 \mathrm{c}^{* *}$ \\
2 (BGF 14-039) & $2,02 \mathrm{a}^{* *}$ & $1,41 \mathrm{ab}^{* *}$ & $0,2223 \mathrm{a}^{* *}$ & $2,2085 \mathrm{a}^{* *}$ \\
$\mathbf{3}$ (BGF 14-230) & $1,91 \mathrm{~b}^{* *}$ & $1,36 \mathrm{~b}^{* *}$ & $0,2046 \mathrm{~b}^{* *}$ & $2,0467 \mathrm{~b}^{* *}$ \\
\hline CV (\%) & 7,41 & 8,04 & 1,73 & 0,24 \\
\hline
\end{tabular}

Médias seguidas por mesma letra nas colunas não diferem entre si, pelo teste de Tukey a $1 \%$ (**). Médias seguidas por mesma letra nas colunas não diferem entre si, pelo teste de Tukey a 5\% (*). CS= Comprimento da semente; LS= Largura da semente; Peso de 100 sementes; Peso de 1000 sementes.

\section{Viabilidade de sementes e multiplicação}

Não houve diferença significativa para os resultados de \% de germinação total e nos demais parâmetros que avaliam a cinética da germinação das sementes dos acessos estudados (Tabela 3). De forma descritiva o desempenho das sementes do acesso 2, de procedência de Canarana/BA, foram aquelas que apresentaram as menores médias (52\%), maior tempo médio (3,40 dias) e menor velocidade de germinação. Em comparação, sementes dos acessos 1 e 3 mostraram germinação semelhantes estatisticamente (64 e 77\%, respectivamente) e comportamento cinético bem próximos. Em média, sementes desses dois últimos acessos mostraram uma germinação rápida, requerendo em torno de 2,6 dias para que houvesse a emissão da raiz inicial $(>2 \mathrm{~mm})$. Considerando as condições de armazenamento (potes herméticos com sílica gel) e o tempo de armazenamento das sementes estudadas (desde 2015), os resultados obtidos nesse estudo confirmam a manutenção da viabilidade e o potencial germinativo das sementes.

Pelo teste de germinação as sementes do acesso 3 foram as que apresentaram a maior porcentagem de sementes germinadas, e que nesse caso não foi possível associar com as maiores dimensões (C x L) e peso de 100 e 1000 sementes (Tabela 2). Através desse estudo foi observado que a conservação de sementes do gênero Stylosanthes é viável, e que a manutenção do CU baixo $(<5 \%)$ é um requisito importante para a longevidade das sementes mesmo quando a temperatura é ambiente (laboratório).

Tabela 3. Valores médios e percentuais, e parâmetros cinéticos da germinação de sementes de Stylosanthes

\begin{tabular}{lccl}
\hline Acesso & $\begin{array}{c}\text { G } \\
\text { (\%) }\end{array}$ & $\begin{array}{c}\text { TMG } \\
\text { (dias) }\end{array}$ & \\
\hline 1 (BGF 14- P115-2) & $64,00 \mathrm{a}^{* *}$ & $2,77 \mathrm{a}^{* *}$ & $0,39 \mathrm{a}^{* *}$ \\
$\mathbf{2}$ (BGF 14-039) & $52,00 \mathrm{a}^{* *}$ & $3,40 \mathrm{a}^{* *}$ & $0,31 \mathrm{a}^{* *}$ \\
$\mathbf{3}$ (BGF 14-230) & $77,33 \mathrm{a}^{* * *}$ & $2,52 \mathrm{a}^{* *}$ & $0,40 \mathrm{a}^{* *}$ \\
\hline CV (\%) & 20,55 & 26,98 & 31,47 \\
\hline
\end{tabular}

\section{Caracterização morfológica das mudas}

A Tabela 4 mostra os resultados obtidos para os descritores morfológicos $(p<0,01)$. Com exceção do comprimento e largura do folíolo central, os demais parâmetros mostraram coeficiente de variação elevado $(\mathrm{CV}>32$ e $<51 \%)$ justificado pelo material não uniforme o que requer um número maior de sementes e plantas a serem amostradas.

Para a variável altura (ALT), mudas do acesso 3 mostraram as melhores médias (15.8 $\mathrm{cm}$ ), e o acesso $2 \mathrm{com}$ média de $4.3 \mathrm{~cm}$. Vale ressaltar que o acesso 2, trata-se de uma espécie que apresenta hábito de crescimento de porte rasteiro, diferenciando-se dos demais. Destacamos ainda que as plantas do acesso 2 apresentaram melhores médias de comprimento (com 4,1 mm) como para largura (com 4,4 mm), indicando que os tamanhos dos folíolos se modificam nas diferentes condições e/ou com a idade das plantas. Em relação ao número de 
folhas ( $\mathrm{N}^{\mathrm{o}}$ FOL), os acessos 1 e 3 obtiveram as melhores médias (18 e 12, respectivamente) e não diferem significativamente entre si. Plantas do acesso 2 mostraram número de folhas com a média bem inferior $(5,1)$, sendo que esse número reduzido de folhas bem como a altura da planta pode ser atribuído ao porte rasteiro da espécie. Plantas do acesso 3 apresentaram as melhores médias em diâmetro, o que provavelmente contribuiu para a obtenção de mudas maiores e mais vigorosas.

Tabela 4. Valores médios e percentuais de características morfoagronômicas de Stylosanthes.

\begin{tabular}{lccccc}
\hline Acesso & $\begin{array}{c}\text { ALT } \\
(\mathbf{c m})\end{array}$ & $\begin{array}{l}\text { COMP } \\
(\mathbf{m m})\end{array}$ & $\begin{array}{c}\text { LARG } \\
(\mathbf{m m})\end{array}$ & $\begin{array}{c}\mathbf{N}^{\circ} \text { FOL } \\
(\mathbf{u n d})\end{array}$ & $\begin{array}{l}\text { DIAM } \\
(\mathbf{m m})\end{array}$ \\
\hline $\mathbf{1}$ (BGF 14- P115-2) & $10,52 \mathrm{~b}^{* *}$ & $3,18 \mathrm{~b}^{* *}$ & $3,39 \mathrm{~b}^{* *}$ & $17,92 \mathrm{a}^{* *}$ & $1,29 \mathrm{~b}^{* *}$ \\
$\mathbf{2}$ (BGF 14-039) & $4,33 \mathrm{c}^{* *}$ & $4,14 \mathrm{a}^{* *}$ & $4,37 \mathrm{a}^{* *}$ & $5,07 \mathrm{~b}^{* *}$ & $1,18 \mathrm{~b}^{* *}$ \\
$\mathbf{3}$ (BGF 14-230) & $15,75 \mathrm{a}^{* *}$ & $3,02 \mathrm{~b}^{* *}$ & $3,25 \mathrm{~b}^{* *}$ & $12,23 \mathrm{a}^{* *}$ & $1,94 \mathrm{a}^{* *}$ \\
\hline \multicolumn{1}{c}{ CV(\%) } & 47,08 & 14,52 & 16,17 & 50,86 & 31,94 \\
\hline
\end{tabular}

Médias seguidas por mesma letra em cada colunas não diferem entre si, pelo teste de Tukey a 1\% (**). Médias seguidas por mesma letra em cada colunas não diferem entre si, pelo teste de Tukey a 5\% (*). ALT= Altura; COMP= Comprimento do folíolo central; LARG= Largura do folíolo central; $\mathrm{N}^{\circ} \mathrm{FOL}=$ Número de folhas; DIAM= Diâmetro.

\section{CONCLUSÃO}

A variabilidade genética encontrada nos acessos de Stylosanthes é importante para a seleção de genótipos promissores ao melhoramento genético da espécie. $\mathrm{O}$ acesso 2 apresentou melhores médias para os dados biométricos. Para a etapa de germinação e qualidade fisiológica das sementes, os resultados não diferiram. Para a caracterização morfoagronômica o acesso 3 (BGF 14-230) mostrou os melhores resultados de mudas maiores e mais vigorosas. Ações de manutenção da viabilidade das sementes devem ser mantidas para que a "Coleção de Trabalho de espécies forrageiras do Horto Florestal possa ser registrada futuramente.

\section{REFERÊNCIAS}

ARAÚJO, E.F. et al. Avaliação de diferentes métodos de escarificação das sementes e dos frutos de Stylosanthes viscosa Sw. Revista Brasileira de Sementes, v.22, n.1, p.18-22, 2000.

BRASIL. Ministério da Agricultura, Pecuária e Abastecimento. Regras para análise de sementes. Brasília: Mapa/ACS, 2009. 399p.

COSTA, N. M. S. Revisão do gênero Stylosanthes Sw. 2006. 47f. Tese (Doutorado em Engenharia Agronômica) - Universidade Técnica de Lisboa, Lisboa. 2006.

DEMINICIS, B. B. et al. Superação da dormência de sementes de oito leguminosas forrageiras tropicais. Archivos de Zootecnia. v.55, n.212, p.401-404, 2006.

KARIA, C.T. Caracterização genética e morfoagronômica de germoplasma de Stylosanthes guianensis (Aubl.) SW. 2008. 138f. Tese (Doutorado em Agronomia). Universidade Federal de Goiás, Goiânia, Brasil. 2008.

OLIVEIRA, R.S; QUEIRÓZ, M.A. Banco ativo de germoplasma de Stylosanthes spp. da Universidade Estadual de Feira de Santana - BA. Revista RG News, v.2, n.2, p.119-128, 2016.

Stylosanthes in Flora do Brasil 2020 em construção. Jardim Botânico do Rio de Janeiro. 